\title{
Enhancing Pre-service Teachers' Reflective Quality on Inquiry-based Teaching Through a Community of Practice
}

\author{
Jeerawan Ketsing ${ }^{1 *}$, Noriyuki Inoue ${ }^{2}$, Sandy Buczynski ${ }^{3}$ \\ 'Department of Education, Faculty of Education, Kasetsart University, Bangkok, Thailand, ${ }^{2}$ Faculty of Human Sciences, Waseda University, Japan, \\ ${ }^{3}$ Department of Learning and Teaching, School of Leadership and Education Sciences, University of San Diego, CA, United States
}

*Corresponding Author: fedujwk@ku.ac.th

\section{ABSTRACT}

Implementing inquiry-based teaching in secondary school is often a challenge for pre-service teachers. Thoughtful reflection on their teaching experience may help future teachers address this challenge. This article examined the quality of reflection on inquiry teaching by two pre-service science teachers as they participated in a mini-Community of Practice (mCoP) with their cooperating teachers and university advisor. Findings from this study revealed the benefits of this mCoP for nurturing pre-service teachers' inquiry teaching by building a network of encouraging support from experienced teachers and by providing a supportive reflective environment. The study also showed pre-service teachers transformed their reflections from technical to reflective thinking as they matured in inquiry-based teaching practice.

KEY WORDS: community of practice; inquiry-based teaching; pre-service teacher; reflection

\section{INTRODUCTION}

^ nquiry-based learning has long been accepted as a fundamental approach for teaching science in many countries (Abd-El-Khalick et al., 2004; Ministry of Education, 2017; NRC, 2013). Unfortunately, creating true classroom inquiry is known to be a huge challenge for preservice teachers (Kang et al., 2013; Yoon et al., 2012). As a matter of fact, since scientific inquiry has been promoted in science curriculum and standards (Abd-El-Khalick et al., 2004; NRC, 2000), it has been documented that pre-service teachers struggle to transform this pedagogical approach in real settings (Inoue and Buczynski, 2011; Kang et al., 2013; Yoon et al., 2012).

Fortunately, the literature recommends that pre-service teachers are likely to overcome the difficulty of inquiry teaching when having opportunities to design inquiry lesson, teach this lesson in a real setting, and reflect upon the teaching experience (Lotter and Miller, 2017; Zembal-Saul et al., 2000). For ensuring learning in this process, the teachers are required to use a high level of reflection for evaluating the experience and constructing new insights based on that experience (Dewey, 1933). Reflection on practice is defined as a means of self-examination that involves looking back over what has happened in a teaching event in an effort to improve or encourage professional growth (Moon, 2004; Shulman, 1987). As might be expected, pre-service teachers are known to focus their reflection on technical problems rather than critically analyze how their teaching cultivates children learning (Lotter, 2004; Roy, 2018; Van Manen, 1977). This surface level of reflection acts as a stumbling block for pre-service teachers' growth in terms of knowledge and practice of inquiry pedagogy in a real context.

Then what does it take to help pre-service teachers move on from focusing on the technical aspects of teaching in their reflective practices? How would an improved quality of a preservice teacher's reflection profoundly improve their inquiry teaching approach? This is an important issue for us since a high-quality level of reflective thinking implies that a future teacher would be capable of sustainable improvement in their inquiry-based teaching.

This study aimed to address developing an appropriate model for guiding pre-service teachers through the challenges of implementing inquiry pedagogy by focusing on the quality of the future teachers reflection on their teaching experiences. Specifically, the study sought to address the research question "In what ways do science pre-service teachers transform their reflective quality (if any) as they develop a deeper understanding of inquiry in the context of a minimal Community of Practice?"

\section{LITERATURE REVIEW}

\section{Theoretical Lens for Reflective Quality}

The notion of adult learning to renew oneself through critical reflection can be described using the lens of transformative learning theory. According to Mezirow (1995), transformative learning is the process in which adult learners modify or change their underlying assumptions of the world (in this study, inquiry-based teaching) when faced with disorienting dilemmas. This dilemma creates a conflict experience when 
compare with our preconceptions and it leads us to reconsider and evaluate the accuracy of our assumptions and beliefs about the world. In this study, the disorienting dilemmas refer to puzzling experiences by which the pre-service teachers encounter when trying to teach science through inquiry in a real context. Mezirow (1997) views critical reflection as a central of self-transformation and he believes it should be done under the context of problem-solving and communicative dialogues with others (in this study, a community of practice). Moreover, this kind of dialogue can promote learning when it goes beyond simple description and ventures into transformation.

Two theoretical lenses were employed for justifying the pre-service teachers' reflective quality. The first lens derives from a group of scholars who believe the quality of reflection should be determined by the domain of reflection, or "content of reflection" (Lane et al., 2014). Researchers in this group agree that reflective practitioners should focus their reflection on three domains: Technical, practical, and critical reflection (LaBoskey, 1994; Larrivee, 2008). Technical reflection refers to how well teachers examine their practice to promote children's learning in accordance with the desired outcome (Goodman, 1991; LaBoskey, 1994). From this viewpoint, teachers analyze teaching experiences by focusing on the methods and strategies used for reaching certain goals. Practical reflection is concerned with teachers evaluating their teaching experiences by seeking to bridge a gap between theories and practices. In other words, teachers reflect on what they would like to do and what they can do. Teachers in this domain tend to support their decisions on teaching actions with logical reasoning, rather than intuition (Goodman, 1991; La Boskey, 1994; Larrivee 2008). The last domain of reflection calls "critical reflection" (Goodman, 1991; LaBoskey, 1994; Larrivee, 2008). It is concerned with a broader context by which teachers address how well their practices contribute toward equity, social justice, and humane conditions in society. From this perspective, teachers view classroom and school as a place for preparing good citizens to function in society.

The second theoretical lens draws from another group of researchers who propose that quality of reflection should be assessed by considering the language used for argumentation, so-called "depth of reflection" (Lane et al., 2014): Description, justification, critique, and discussion (Hatton and Smith, 1995; Leijen et al., 2012; Lotter and Miller, 2017). The lowest level of reflection is called "description." It happens when teachers describe their actions in classroom without critiquing or supporting the statements with reason. Justification is when teachers back up their reflective dialogues with a logical reason. Critique refers to a kind of statement by which teachers evaluate their actions and provide an explanation on it. For discussion, it happens when teachers propose new way for doing things in classroom and support it with a logical reason. An adult who transforms the most is one who can analyze his/ her experience with high levels of argumentation.

\section{Inquiry Pedagogy is the Goal}

The common consensus on inquiry-based teaching is that it is student-centered. During inquiry lessons, learners pose questions, conduct scientific investigations based on their generated questions, build ideas around the results of their investigation and prior knowledge related to science, and communicate their ideas with others for justification (Hansen et al., 2015). This approach contrasts with traditional, teachercentered teaching, where the teacher presents facts and conveys their knowledge about the content. Throughout the inquiry lesson, students investigate a phenomenon and the teacher guides their learning through questioning and providing resources.

New teachers usually struggle with this approach of teaching because it is different from the way that they were taught, and it means shifting control from teacher-centered instruction to student-centered learning. According to Inoue and Buczynski (2011), pre-service teachers struggle to consider the multiple issues that are key for a successful inquiry lesson, limiting their ability to implement effective inquiry lessons. One way to address these issues is through the reflective support that communities of practice $(\mathrm{CoP})$ in University training programs can provide.

\section{CoP Provides Supportive Environment}

One thing that pre-service teachers are immersed in through their University training is a community of practice. This community consists of educators at various levels in their teaching career - beginning, practicing, teacher educators, etc. This community offers a safe and helpful environment for new teachers to voice their concerns and veteran teachers to offer advice. According to Lave and Wenger (1991), beginners learn to become full members of a community of practice $(\mathrm{CoP})$ when working with experts within a community (school, in our case). CoP is built on the idea of distribution of knowledge (Jones et al., 2013). A CoP is a joint enterprise that is continually renegotiated by its members. This mutual engagement binds members together into a social entity that promotes the collective responsibility for student learning and improves teacher practices (Buczynski and Hansen, 2014). CoP is characterized by promoting collaboration, integrating collective and individual learning, increasing reflective professional inquiry, and building on the foundation of members' shared values and vision (Buczynski and Hansen, 2014; Wenger and Trayner, 2015).

\section{METHODOLOGY}

This study was conducted under interpretive methodology (Gallagher and Tobin, 1991) as we aimed to understand the way in which the two pre-service teachers constructed meanings of their inquiry teaching experiences through reflections while working with experts within a CoP. We began our study with an assumption that the pre-service teachers already had preconceptions regarding inquiry pedagogy. The challenge was to track how their understandings of inquiry pedagogy 
changed overtime during the CoP program. For Lincoln and Guba (1985), multiple realities in social phenomena should be captured using qualitative methods. Thus, findings from this study were elicited from reflective journals and interviews with pre-service teachers. All interviews were audio-recorded and took about 30 minutes.

\section{Community of Practice Program Context of CoP in this study}

According to Wenger and Trayner (2015), three fundamental components for forming a $\mathrm{CoP}$ are domain, community, and practice. Domain refers to shared interest and goal among the community members. Community is defined as a group of people who regulatory engage in activities and discourses for build-up relationship and reach up proficient level of the shared interest. Practice means the community members are practitioners who attempt to solve practical problems by taking action and conducting group reflection.

We defined our group as CoP since the five members set up a shared domain of interest in facilitating the two pre-service teachers' ability to teach inquiry. The two pre-service teachers were newcomers in the context of field experience school who practiced inquiry under the consultation of veteran members of the community - two cooperating teachers and one university advisor (Lave and Wenger, 1991). Because our community consisted of only five individuals, we added the prefix "minimal" to our Community of Practice (mCoP). The learning tasks involved the future teachers to face with practical problems or disorienting dilemmas in Mezirow's perspective (1995), examine new ideas in practice and reflect upon its outcome to improve the teacher practices.

The mCoP program took place in a lower secondary school in a suburban area of Bangkok, Thailand. Two 22-year-old female pre-service teachers, Malee and Milin (pseudonyms), volunteered to participate in this study. They were in their last year of a 5-year bachelor's degree program of education in a public university in Bangkok. The participants were selected because: (1) They were willing to join this program with the shared interest in inquiry-based teaching, (2) they were teaching science in the same field experience school so they could learn from each other, and (3) their cooperating teachers acknowledged having experience in inquiry teaching. The pre-service teachers taught science three periods a week, at $60 \mathrm{~min} /$ period.
In the current study, we chose to employ the mCoP within one field experience school rather than expand it into many schools at once because of several reasons. First, we wanted to gain in-depth information on how individual pre-service teachers transform their reflective thinking as they went through the mCoP. Second, we believed a small-scale, minimal community would allow us to easily capture the social dynamic in the community, and then we could promptly adjust the practice to fit individuals' needs while running activities in the $\mathrm{mCoP}$. Third, we learned from literature that a low level of support from cooperating teachers was one of the major factors hindering pre-service teachers' inquiry teaching (Smith and Engenmann, 2015; Roy, 2018). As such, this study attempted to minimize this feasibility challenge by choosing a school in which its cooperating teachers were willing to provide on-going support for the teacher candidates. This notion is in line with the core concept of $\mathrm{CoP}$ by which newcomers learn from veteran members under the condition that everyone has shared value and concern as a key essence of $\mathrm{CoP}$ (Lave and Wanger, 1991). Finally, with this minimal size, if the mCoP model is effective, then others would find it easy to apply it in their contexts with less effort than a larger CoP. In other words, a mini-scale model may help to enrich the degree of transferability of this CoP model into another context.

\section{CoP activities}

A minimal CoP was our intention since it provided an opportunity for in-depth information on the pre-service teachers' reflective thinking on the inquiry teaching experiences. The $\mathrm{mCoP}$, if effective, also leads to a new framework for teacher educators to model in supporting pre-service teachers' inquiry teaching. All veteran members took the role of supporter for the pre-service teachers' learning to teach inquiry, rather than an evaluator (Lave and Wenger, 1991). The community members engaged in a series of activities throughout an 18 week-long (May to September) of the first semester of the school year. The activities are summarized in Figure 1.

The first set of activities involved observing the cooperating teachers' inquiry teaching and helping the veteran teachers prepare laboratories. Afterward, the pre-service teachers designed their own inquiry lesson plans using advice from their cooperating teachers. They then implemented the lessons individually while the rest of CoP members observed their teaching. An individual interview with the pre-service

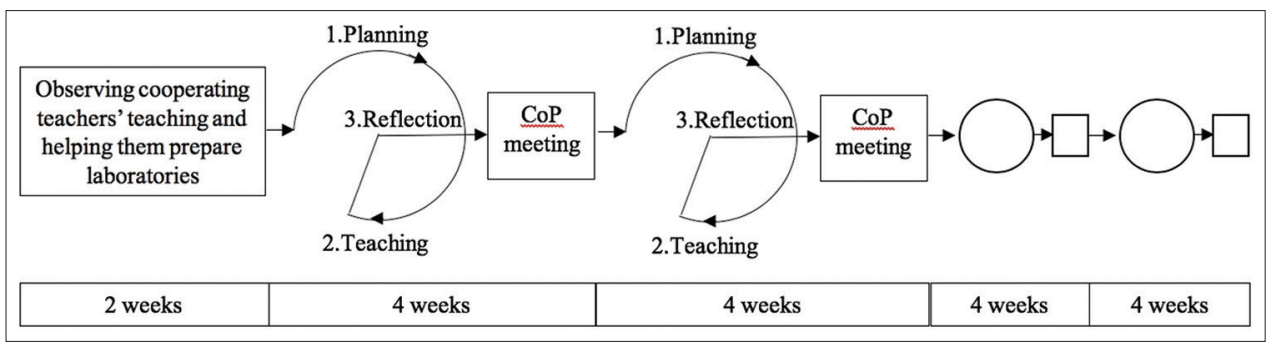

Figure 1: A summary of activities inside the mCOP program 
instructor was conducted right after the observed lesson for probing her thoughts on the teaching experience. See appendix for interview protocol.

Once finished with a teaching event, all members of the CoP were invited to join the meeting in which everyone engaged in collaborative reflection regarding the observed lessons. For a fruitful reflection, the $\mathrm{mCoP}$ members applied the interview questions for constructing communicative dialogue. Lesson plans and observation field notes were used as a media for reflection. For reducing a sense of failure among the preservice teachers, all members provided kind feedback on the taught lesson to the pre-service instructors. Each meeting took approximately 2 hours.

After the meeting, the pre-service teachers were asked to write a reflective journal in response to a set of guiding questions like the interview protocol. Later, the pre-service teacher applied the lessons learned from the reflection to design a new lesson plan and subsequently implemented the lesson in the next cycle. Eventually, the pre-service teachers engaged in four cycles of co-planning, teaching, and reflection on their inquiry-based lesson.

\section{Data Collection and Analysis}

The reflective journal was used as the main data source for tracking the pre-service teachers' reflective thinking on their teaching experiences. Each pre-service teacher wrote four journal entries. They recorded in their journal after teaching. The content analysis method (Densombe, 2014) was used to analyze the data. Two theoretical lenses were employed for identifying the pre-service teachers' reflective quality. These lenses focused on the domain of reflection (technical, practical, and critical) and argumentative language for reflection (description, justification, critique, and discussion). We utilized these two theoretical lenses because we agree with Leijen et al. (2012) that we need to examine how broad and how deep the pre-service teachers' thoughts are about their teaching experiences. We collected empirical data directly derived from the pre-service teachers' thinking (interview and reflective journal) for avoiding limitation of self-report survey.

The analytical procedure consists of seven steps adapted from Densombe (2014). First, all data sources were organized sequentially according to the time of the lesson implementation. Second, the first author and a research assistant examined interrater reliability of the coding through independent reading of each data set several times to get a sense from the data and to define the units of analysis. Third, we freely read and re-read the data to assign codes for the units of analysis with which we found relevant to the analytical framework. Fourth, codes and categories were shared with the second and third authors and we discussed what should be included in each code and category. At this point, we noticed that many of the units of analysis fell into the technical domain; thus, we decided to dig deeper into this domain for probing the areas in which the pre-service teachers' reflections concentrated. Fifth, the first researcher and a research assistant once again independently analyzed all data set using the consensus codes and categories. Once finished, the tentative findings were shared with the second and third authors. We discussed these findings to reach an agreement and then grouped relevant codes into categories. We developed new sub-categories as needed in the technical domain. Sixth, the first researcher and a research assistant rechecked each category and sub-category by searching for data that went against the working hypotheses. Finally, we computed number of the units of analysis in each category because it implied the areas of concern of the preservice teachers. Table 1 shows the final version of codes and categories.

\section{Demographic Information of the Inquiry Lessons}

Table 2 provides demographic information of the implemented lessons of the two pre-service teachers Malee and Milin. Throughout the mCoP, Malee and Milin designed four inquiry lessons planned using the 5Es instructional model (Bybee et al., 2006) because the model has been promoted by Ministry of Education $(2002 ; 2017)$ as a fundamental approach for teaching science in Thailand. The model consists of five stages: Engagement, exploration, explanation, elaboration, and evaluation.

As shown in Table 2, grade levels and teaching topics of the two pre-service teachers were different. We admit that this difference may influence the quality of the teacher candidates' reflective thinking. However, the children at this age share the same stage of cognitive and emotional development (Piaget, 1961; Saarni, 2000), and we assumed that the impact of this is not significant in this study. As such, the pre-service teachers are able to apply what they learn from psychological studies of teaching and learning into their own teaching contexts, and we hypothesized some degree of contextual diversity could be good food for promoting divergent thinking and thoughtful reflection in the $\mathrm{CoP}$ activities. In addition, it was our intention to provide the pre-service teachers flexibility and opportunities to choose a topic in which they felt comfortable, rather than force them to focus on the same topic, as we learned from the literature that the lack of teachers' content knowledge can be a major barrier for the novice teachers' learning on how to teach inquiry (Roehrig and Luft, 2004).

\section{FINDINGS}

\section{Domain of Reflection}

Technical domain: Table 3 shows numbers of the pre-service teachers' reflection that correspond with the three domains technical, practical, and critical. The numbers were counted from the units of the analysis found in the pre-service teachers' reflective journals and interview transcripts. The findings from the four-lesson implementation indicate that most of the preservice teachers' reflective statements fell into the technical domain (40 and 43 units, respectively). The two teachers typically thought about their teaching experiences by focusing on the effectiveness of the teachings on children's learning to achieve the classroom learning objectives. 


\section{reflection

\begin{tabular}{lll}
\hline Code & Category & \\
\hline TR & Technical reflection \\
& The domain of reflection in which the pre \\
focuses on how well the teaching experie & to achieve the expected learning outcomes \\
reflects upon how effective her learning & instructional media, or classroom manag \\
understand content knowledge, develop & \\
Sub-category: The code of sub-category & \\
of reflection in which the pre-service teact & \\
on. & \\
TRC & $=$ Content knowledge \\
TRTM & $=$ Time management \\
TRH & $=$ Hands-on activity \\
TRI & $=$ Student interest/enjoyment \\
TRLO & $=$ Learning objectives \\
TRQ & $=$ Questioning technique \\
TRIM & $=$ Instructional media \\
TRGW & $=$ Group work
\end{tabular} \\ PR Practical reflection}

Table 1: Codes and categories of domain and level of

The domain of reflection in which the pre-service teacher focuses her thinking on how well her teaching practices link to theories, in this case inquiry-based teaching, cognitive constructivist (prior knowledge), social constructivist (group work), individual difference of learners, or teaching methods (role play, model, learning center). Pre-service teacher reflects on her teaching performance by indicating what she would like to do and what she can actually do in her classroom. In this domain, pre-service teacher is able to support her teaching practices with logical reasoning and/or theories rather than intuition.

CR Critical reflection

The domain of reflection in which the pre-service teacher focuses on how appropriate her teaching actions contribute toward, in this case equality, unity, teamwork, or democratic society. For example, pre-service teacher indicates what she missed in classroom for helping students to respect other opinions.

Des Description

The level of reflection in which the pre-service teacher writes or talks about what was going on in her classroom.

Just Justification

It is a higher level of reflection than description. At this level, pre-service teacher uses logical reasoning to support her teaching practices. The future teacher provides explanation on why she did or did not do something in her classroom.

Cri Critique

This level of reflection goes beyond justification. Pre-service teacher does not only support her actions and thinking with sound explanation, but she also evaluates her actions whether it is right or wrong, appropriate or inappropriate, or good or bad.

Dis Discussion

Discussion is the highest level of reflection in which the preservice teacher points out what she wants to change and/or how she is going to make change. At this level, the future teacher may support her alternative approach with a logical reason.

Our analysis shows that Malee's reflection in the technical domain heavily relied on questioning technique $(30.00 \%)$ used during data analysis and conclusion stage (or an explanation stage in the 5Es instructional model (Bybee et al., 2006). As shown in the excerpt from Malee's journal number 1, she pointed out her struggle for helping students analyze data obtained from experiment and link the evidence to the conclusion:

[Guiding question: What is your concern about this lesson?] [I concern about] question that helps students to analyze data and formulate conclusion from the learning activity.

[Guiding question: Why do you have this concern?] I think using all kinds of activities; teachers expect students to understand the purpose of the activities. However, it is difficult for students to make a conclusion from the experiment. Teachers should use driving questions that guide them how to analyze data. Finally, students will be able to form explanation or conclusion of the learning activity or experiment by themselves (Malee's reflective journal on lesson \#1).

Malee was also concerned with providing hands-on activity $(22.50 \%)$ and children learning of content knowledge (17.50\%). If possible, she would like to use learning activities that allow every student to physically engage since she believed it could promote students' constructing of scientific knowledge. The excerpt below evidences Malee's technical reflection in hands-on activities:

[Guiding question: What did you do in this class that supports children learning?] The activity that allowed students to participate in. I used activity that allowed students to learn the concept of states of matter. For teaching the concept of states of matter, I used role play. Students took a role of particles. They displayed how particles set up in each state; solid, liquid, and gas. The students enjoyed playing in the role of particle. With this activity, they learned the concept by themselves (Malee's reflective journal on lesson \#3).

Although most of Malee's reflective statements were classified as technical domain, she rarely mentioned a logistic issue, like time management $(7.50 \%)$.

For Milin, most of her reflection focused on teacher questions (27.90\%). She was concerned with her questions throughout the classroom instruction. Milin pointed out her difficulty to propose questions that guide students to connect their ideas from engagement stage, exploration stage, and explanation stage of the 5Es model. As shown in her reflective journal, "[Guiding question: What would you like to improve in this lesson?] I would like to improve my question, particularly in the lesson introduction stage and teaching stage. I felt it is not smooth. Students confused. I would like to improve my question" (Milin's reflective journal on lesson \#1).

In addition, this future teacher was worried about instructional media $(25.58 \%)$ and time management (11.63\%). She mentioned the effectiveness of using video clip and worksheet during engagement and exploration stages of the 5Es model for motivating students' interest and learning scientific concept. The excerpts below demonstrate Milin's technical reflection on instructional media: 


\begin{tabular}{|c|c|c|c|}
\hline \multicolumn{2}{|c|}{ Demographic information of implemented lessons } & \multirow{2}{*}{$\begin{array}{l}\text { Malee } \\
\text { 8th Grade }\end{array}$} & \multirow{2}{*}{$\begin{array}{l}\text { Milin } \\
\text { 7th Grade }\end{array}$} \\
\hline Grade level & & & \\
\hline Class size & & 29 students (16 girls, 14 boys) & 25 students ( 7 girls, 18 boys) \\
\hline \multirow[t]{2}{*}{ Lesson \#1 } & Topic of study & Diffusion & Respiratory system \\
\hline & Main activity & Demonstration and experiment & Watching video clip and drawing concept map \\
\hline \multirow[t]{2}{*}{ Lesson \#2 } & Topic of study & Biotechnology & Excretory system \\
\hline & Main activity & Learning center & Learning center \\
\hline \multirow[t]{2}{*}{ Lesson \#3 } & Topic of study & States of matter & Animal behaviors and adaptation \\
\hline & Main activity & Role play and bead model & Lecture and discussion \\
\hline \multirow[t]{2}{*}{ Lesson \#4 } & Topic of study & Homogeneous substance & Addictive substances \\
\hline & Main activity & Experiment for identifying unknown substances & Classification of addicted-drug cards \\
\hline
\end{tabular}

Table 3: Domain of reflection of the pre-service teachers

\begin{tabular}{|c|c|c|c|c|c|c|c|c|c|c|}
\hline \multirow[t]{2}{*}{ Domain of reflection } & \multicolumn{5}{|c|}{ Number of units of analysis of Malee's reflection } & \multicolumn{5}{|c|}{ Number of units of analysis of Milin's reflection } \\
\hline & $\mathbf{L 1}^{1}$ & $\mathrm{~L}^{2}$ & L3 & L4 & Total & $\mathrm{L}^{1}{ }^{1}$ & $\mathbf{L}^{2}$ & L3 & L4 & Total \\
\hline Technical & 16 & 8 & 10 & 6 & 40 & 14 & 0 & 14 & 15 & 43 \\
\hline practical & 2 & 1 & 7 & 2 & 12 & 1 & 4 & 4 & 2 & 11 \\
\hline critical & 0 & 0 & 0 & 3 & 3 & 0 & 1 & 0 & 1 & 2 \\
\hline
\end{tabular}

${ }^{1} \mathrm{~L} 1$ stands from lesson number 1. L2 stands from lesson number 2 and so on. ${ }^{2}$ The number of L2 is decreased because we lost the interview data with the pre-service teachers due to a technical problem with tape recorder.

[Guiding question: What did you do in this class that supports children learning?] The use of instructional media about bird migration, it motivated student curiosity and interest. The students paid attention while watching the video clip. The use of pictures also helped me to capture their intention in my class (Milin's reflective journal on lesson \#3).

However, she showed minimal concern with learning objectives $(9.30 \%)$, content knowledge $(9.30 \%)$, and handson activity $(9.30 \%)$ when compare with other sub-categories.

Practical and critical domains: According to Table 3, when we looked closely to the data, it was found that in lessons number 3 and number 4, the pre-service teachers geared their focus of reflection from the technical domain toward practical and critical domains. In her lesson number 3, Malee talked about the pros and cons of using the role-play learning activity and a bead movement model for teaching the concept of states of matter. The excerpt below illustrates her practical reflection on the decision she made for choosing both learning activities in one lesson.

In a similar vein, Milin's reflective statements in her lesson number 4 show that she evaluated the way in which her teaching failed to link the learning activities with children' prior knowledge. The excerpt below shows Milin's practical reflection regarding a new technique she would use for helping students bridge new learning experiences with prior knowledge.

The results in Table 3 also show that the pre-service teachers gradually broadened their focus of reflection to covering the three domains, particularly in the last lesson. Malee began to see her class as a place not only for learning science but also for demonstrating a democratic society where every voice should be heard and respected. She wrote:

\begin{tabular}{ll}
\hline Interviewer & I am wondering why you choose two activities: Role \\
play and bead model? How are they difference? \\
Why do not you select only one?
\end{tabular}

\begin{tabular}{ll}
\hline Interviewer & Generally speaking, do you think your class today \\
& represents inquiry-based learning? \\
\hline Milin & I think it is an inquiry, though it is not in a full option. \\
& I think I miss a link between new knowledge and prior \\
& knowledge. My question is unclear. It is not systematically \\
& organized ... [In the future] I will use the questions posted \\
& during the lesson introduction again in the conclusion \\
& stage. Students may write answers in their worksheet or \\
& talk in classroom discussion. By doing so, they can see how \\
& their answers change when compare with their answers at \\
& the beginning (Milin's interview response in lesson \#4)
\end{tabular}


[Guiding question: What did you do in this class that did not support children learning? And you would choose not to do it again.] There was a group of students obtained data that different from the majority. However, I did not ask them to discuss the cause of difference. At that time, I decided to use the data from the majority of student groups. I cut out the alternative data set. It seemed like I force minority students to accept data from other groups. I should not practice this way because the students may misunderstand the spirit of science (Malee's reflective journal on lesson \#4).

For Milin's last inquiry lesson, she began to see the benefit of group work on building a sense of friendship and unity among students. The statement below presents Milin' critical reflection on her teaching experiences regarding to group work:

[Guiding question: What did you do in this class that you would choose to do it again in the future?] The activity that allows students to work in group. Because group work helps students to work in systematic manner. I used activity that allowed students to work in group because group work helps students to learn in systematic manner. By working in group, students have a chance to exchange ideas. It also promotes group unity and friendship (Milin's reflective journal on lesson \#4).

In summary, the findings reveal that when participating in the $\mathrm{mCoP}$, the pre-service teachers' reflective thinking mainly placed emphasis on a technical domain, especially the questioning technique that the teachers used in class. However, within the last two lessons, the pre-service teachers expanded their focus of reflection from the technical domain to practical and critical domains. They presented a deep reflection on the interaction between their inquiry-based teaching and students' learning of science and learning to become good citizens.

\section{Level of Reflection}

Table 4 shows the numbers of the pre-service teachers' reflection in correspondence with the argumentative framework. The numbers were counted from the units of analysis found in the pre-service teachers' reflective journals and interview transcripts. Using this framework for identifying reflective quality, the pre-service teachers' reflection was divided into four categories: description, justification, critique, and discussion (Hatton and Smith, 1995; Leijen et al., 2012; Lotter and Miller, 2017). With this framework, teachers who reached a high-quality level of evaluating the effectiveness of their teachings provided a sound explanation for their actions and proposed new ways of teaching in the future classroom.

According to Table 4, the findings reveal that the pre-service teachers' reflective thinking heavily fell into a critique level (17 and 18 units, respectively). At this level, Malee and Milin were able to evaluate the appropriateness of their teaching practices on supporting children learning. They can use logical reasons to back up their actions or ideas. However, when we dug deeply into the data for an identifying trend or distribution among the four categories, it was found that most reflective statements went beyond description. The pre-service teachers did not merely explain what had happened in classrooms; rather, they provided reasons behind the teaching actions (justification), assessed the effectiveness of the teachings (critique), and expressed intention or ideas for improving their teachings (discussion).

In general, the reflective statements of both pre-service teachers were likely to go beyond the description level after they reached the practice of inquiry-based teaching in lesson number 3. For instance, lesson number 3 illustrated Malee's reflection in "justification level" in which she used logical reasoning to support her teaching practice. Malee explained the reason she decided to use two learning activities (role play and bead model) instead of one. The teacher supported her decision with the pros and cons of each activity in relation to student learning, as shown in her interview response to lesson number 3 provided previously.

Lesson number 4 showed her reflection in "critique level" in which the teacher did not only support her action with a sound reason but also evaluate the value of that action. As shown in the excerpt from Malee's journal number 4, she indicated her wrong decision on data choices. The teacher stated she should involve both mainstream and alternative data in her classroom discourse since science requires evidence and explanation:

[Guiding question: What did you do in this class that did not support children learning?] There was a group of students obtained data that different from the majority. However, I did not ask them to discuss the cause of difference. At that time, I decided to use the data from the majority of student groups. I cut out the alternative data set. It seemed like I force minority students to accept data from other groups. I should not practice this way because the students may misunderstand the spirit of science (Malee's reflective journal on lesson 4).

Table 4: Level of reflection of the pre-service teachers

\begin{tabular}{|c|c|c|c|c|c|c|c|c|c|c|}
\hline \multirow[t]{2}{*}{ Level of reflection } & \multicolumn{5}{|c|}{ Number of units of analysis of Malee's reflection } & \multicolumn{5}{|c|}{ Number of units of analysis of Milin's reflection } \\
\hline & L11 & $\mathrm{L}^{2}{ }^{2}$ & L3 & L4 & Total & L11 & $\mathrm{L}^{2}{ }^{2}$ & L3 & L4 & Total \\
\hline Description & 7 & 1 & 1 & 2 & 11 & 4 & 0 & 6 & 2 & 13 \\
\hline Justification & 1 & 2 & 6 & 3 & 12 & 2 & 0 & 7 & 4 & 12 \\
\hline Critique & 2 & 5 & 6 & 4 & 17 & 7 & 2 & 1 & 8 & 18 \\
\hline Discussion & 6 & 2 & 3 & 2 & 13 & 3 & 3 & 4 & 4 & 14 \\
\hline
\end{tabular}

${ }^{1}$ L1 stands from lesson number 1. L2 stands from lesson number 2 and so on. ${ }^{2}$ The number of L2 is decreased because we lost the interview data with the pre-service teachers due to a technical problem with tape recorder. 
In a similar vein, Milin's interview after lesson number 4 revealed her reflective thinking on justification, critique, and discussion levels. At the critique level, Milin evaluated her lesson and indicated that the lesson failed to construct a new understanding based on children's prior knowledge. She said: "[Interview question: Generally, do you think if this lesson was taught using inquiry-based learning?] I think it is an inquiry, though it is not in a full option. I miss a link between new knowledge and prior knowledge" (Milin's interview response in lesson 4).

At the discussion level, the teacher did not only talk about thing she wanted to change in her class, but she also proposed the way in which it can be changed. As shown in her interview response to lesson number 4, Milin plans to make a flow of questions posted during classroom introduction (engagement stage) and conclusion (explanation stage), and to use worksheet as a thinking tool for the students:

[Interview question: What would you like to improve?] The link between new knowledge and prior knowledge. I will use the questions asked during the lesson introduction to ask again in conclusion. Students may write answers in their worksheet or talk during class discussion. Then, they can see how their answers change, compare with their answers at the beginning [of the lesson] (Milin's interview response in lesson 4).

This finding implies that rich opportunities to engage in cycle of co-planning, teaching, and collaborative reflection on the teaching actions with others inside the $\mathrm{mCoP}$ provide a positive impact on the pre-service teachers' learning to overcome the challenge of inquiry-based teaching.

\section{DISCUSSION}

Many studies consistently agree that reflection is an essential component for pre-service teacher learning in a new pedagogical approach (Gore and Zeichner, 1991; Larrivee, 2008; ZembalSaul et al., 2000). Simply taking actions in a classroom does not guarantee pre-service teachers' learning (Barnett and Friedrichsen 2015; Roy, 2018) because they lack tacit knowledge and experience (Zembal-Saul et al., 2000). Research on teacher development suggests that meaningful reflections on classroom experience can assist teachers to deepen their understanding of teaching and learning (Abell and Bryan, 1997).

For this study, we measured the quality of the two pre-service teachers' reflection under the mCoP experience using two different reflection scales: Domain of reflection (technical, practical and critical) and language used for argumentation (description, justification, critique, and discussion). Based on the findings, the mini-CoP helped the two pre-service teachers to move from a descriptive level of reflection to critique level after going through four cycles of teaching and reflection. For example, Malee critiqued her inappropriate reaction on ignoring data from a group of students who gained a different data set when compared with other groups. Milin evaluated her lesson by focusing on how the lesson support children's learning by connecting the classroom discourse with the student's prior knowledge.

These findings support previous literature in that the difficulty of inquiry teaching can be overcome when pre-service teachers are given opportunities to participate in multiple cycles of plan, teach, and reflect on their own teaching (Lotter and Miller, 2017; Zembal-Saul et al., 2000) under on-going guidance from experienced teachers (Roy, 2018). To promote thoughtful reflection among the $\mathrm{mCoP}$ members, structured reflective practice was created in the form of guiding questions. These questions were important to keep pre-service teachers focused on improving their inquiry teaching. A high-quality level of reflection happens more frequently when the pre-service teachers were asked to envision what they would do in their future classes as a result of the current lesson and consider why they would do it that way. The guiding questions were designed to provoke the pre-service teachers' thinking on how their teaching connected with learning objectives, a child's developmental level, the framework of inquiry teaching, future lessons, and rationale behind actions. We anticipate using this structured reflective practice would help teacher education programs to enrich the teacher candidates' ability to teach inquiry. This finding is consistent with Lotter and Miller (2017) that guidance from facilitators using guided questions plays a significant role in helping science teachers to achieve a high reflective level. Similarly, Borko et al. (2008) reported the usefulness of guided questions on increasing teachers' reflection on children's learning while analyzing videotapes of their instruction.

However, as we know so far, there is not yet a research study on the value of CoP in advancing pre-service teachers' reflective quality of inquiry teaching. Thus, this study presents the benefits of forming a small group community of practice for nurturing the pre-service teachers' inquiry teaching, as seen from the improvement of the future teachers' reflective quality. This desirable outcome may be caused by several reasons. The first factor is the rich opportunities for the pre-service teachers to examine their assumptions and practices of inquiry in a real classroom context. This real setting caused the preservice teachers to face disorienting dilemmas (Mezirow, 1995, 1997) that forced them to use critical reflection and evaluate their preconceptions of inquiry as well as the ultimate goal of school science.

Second, the mCoP created space for pre-service teachers to share ideas and learn from veteran teachers within the community (Lave and Wanger, 1991). Literature indicates pre-service teachers have difficulty thinking critically about their teaching experiences because of their lack of tacit knowledge (ZembalSaul et al., 2000). However, when working closely with veteran teachers in small groups, the pre-service teachers were encouraged to continually think about their teaching scenarios from multiple angles, the cooperating teachers' collective tacit knowledge, and the university advisor's theoretical knowledge. This triad relationship helped to strengthen and mature the preservice teachers' reflective thinking. 
Third, the $\mathrm{mCoP}$ created a structure for the pre-service teachers to practice reflection in a systematic manner. A study by Lotter and Miller (2017) revealed that structured and guided reflective practice is fruitful for shaping the focus of middle school teachers on classroom teaching rather than on logistic (technical) issues associated with the practice. In our study, we used a set of guiding questions (Appendix A) as a thinking tool for the pre-service teachers to diagnose strengths and limitations of their current teaching experiences and to help them envision their future lessons. The guiding questions were used constantly throughout the mCoP, including interview, collaborative reflection, and reflective journal. Previous studies indicate that structured reflective practice is useful for scaffolding the pre-service teachers' self-regulated learning as it challenges them to reshape their own teaching beliefs (Loughran, 2014; Roy, 2018). Besides guiding questions, verbal and written forms of reflection were also available in this $\mathrm{mCoP}$ model. The pre-service teachers were provoked to think about the impact of their teachings on children's learning through verbal reflection using interview and collaborative reflection; they then recorded their final thoughts in reflective journals. This structure of reflection allowed the teacher candidates to systematically process the knowledge learned from teaching experiences. As Gill et al. (2004) point out, systematic processing is crucial for teachers to reflect upon their teaching and to shift their beliefs and practices.

The last factor for encouraging a shift in the pre-service teachers' quality of reflection might be the nature of a relatively small group CoP. With this minimal size, it was easy for its members to form a bounded relationship. For Dewey (1933), thoughtful reflection happens when learners are open mind, pursuing wholeheartedness on a learning task, and seriously taking responsible action to solve problem. To advocate these depositions, a supportive learning environment is required. In doing so, we employed a mini-CoP model since we believed it was likely to formulate a sense of trust among the participants. We recruited members by considering their willingness to learn from one another within a shared domain of interest on inquiry-based teaching (Wenger and Trayner, 2015). Every senior member took the role of mentor rather than judge (Lave and Wenger, 1991). Four basic practices of dialogue (Isaacs, 1999) were applied as a means to create a supportive learning atmosphere. They were deep listening, respecting others, suspending assumptions, and voicing personal truths. These practices helped to release the pre-service teachers' anxiety and formulate a sense of collaboration.

In considering "domain of reflection," the $\mathrm{mCoP}$ helped the two pre-service teachers shift their thinking to a higher level of reflection after only three lesson implementations. This finding suggests that opportunities to apply problem-solving ideas in practical contexts and reflecting upon its outcome are necessary for pre-service teachers to develop knowledge and skills on inquiry teaching (Lotter and Miller, 2017). It also corresponds with Lin et al., (2013) who found that multiple opportunities for participating in collaborative reflection on classroom teachings with peers and experts help teachers improve inquiry practice. What is unique about this CoP that it consisted of only two pre-service teachers, their cooperating teachers, and a university advisor working in a team of five. This provides a new framework for teacher education practice on how to support pre-service science teachers. A mCoP, working together to help pre-service teachers improve the quality and construction of their reflection on the process of inquiry pedagogy. A mCoP worked together to help preservice teachers improve the quality of reflection on their inquiry-based teaching. While the study revealed a great deal of evidence showing that the pre-service teachers presenting surface level of reflection such as time management and content coverage, this finding is in line with previous research on teacher reflection (Gore and Zeichner, 1991; Lotter, 2004; Lotter and Miller, 2017). Nonetheless, this study found a shift in the quality of reflection from the pre-service teachers after three cycles of teaching and reflection.

According to Mezirow (1995; 1997), self-transformation requires adult learners to encounter disorienting dilemmas and use critical reflection to evaluate their current assumptions regarding the phenomena. Findings from this study show that the pre-service teachers expanded their reflective thinking on inquiry teaching as they went through four cycles of designing lesson, facing with a challenge in implementing the lesson, reflecting on its outcomes with experts, and again trying out new ideas in practice. This series of action and reflection allowed the pre-service teachers to test their assumptions on inquiry-based teaching and adjust their preconceptions on the pedagogical approach.

Deep learning happens when a learner engages in thoughtful reflections on their actions (Barnett and Friedrichsen, 2015). This study recommends teacher educators to promote preservice teachers' high-quality reflection by creating a space for novices to learn from experts through communicative dialogues. According to Mezirow (1997), communicative dialogue is essential for self-transformation. It involves adult learners to use critical reflection for evaluating the assumptions underlying their intentions, values, beliefs, and feelings. In this study, collaborative reflection (Lin et al., 2013) was used along with a set of guiding questions for promoting communicative dialogues among the community members. In doing so, the meaning of inquiry teaching was negotiated and co-constructed based on the members' practical experiences. The space for open communication with experienced teachers helped the pre-service teachers to validate their strengths of inquiry teaching and provide solutions for addressing the novice teachers' challenges.

\section{IMPLICATIONS}

This study shows empirical evidence of two pre-service teachers' growth of reflective thinking about their inquiry teaching. It illustrates the value of community in the following recommendations: 
1. Develop a mini-scale community of practice for preservice teachers. This is accomplished by selecting a small number of (a) pre-service teachers teaching in the same school and (b) cooperating teachers who are up to date on inquiry pedagogy and able to devote time and energy to the mCoP. Teacher preparation programs would benefit by establishing a long-term relationship with cooperating teachers and setting up a core value of working together for preparing qualified science teachers. Previous studies support the significant role of cooperating teachers during beginning teachers' transition to become professional teachers (SullivanWatts et al., 2013; Roy, 2018).

2. Provide opportunities for pre-service teachers to work through at least three cycles of plan, teach, and reflect in classroom context for a substantial period of time. This can be done by integrating the cycle into practicum courses, research courses, or field experiences. However, simply taking this series of activities does not guarantee the pre-service teachers' deep reflection and learning (Hatton and Smith 1995; Roy, 2018). Using a set of guiding questions helps to provide structure to the $\mathrm{mCoP}$ and assists with shifting pre-service teachers' reflective thinking to a higher quality level. In addition, we agree with previous literature (Hatton and Smith 1995) that reflective sessions ought to promote both verbal and written reflections, providing opportunities for selfreflection as well as collaborative reflection.

3. Diagnose the quality of reflection on an ongoing basis. The study utilized two theoretical lenses, so-called the "breadth" and "depth" of reflection (Lane et al., 2014) as means to gain in-depth information of the pre-service teachers' thinking about their classroom experiences. This method of collecting and analyzing data helped us to identify areas of strengths and limitations of individual learners. This enables teacher educators to find appropriate solutions for aiding them.

\section{CONCLUSION}

Findings from this study shed some light on the benefits of a mini-CoP for nurturing the pre-service teachers' inquiry-based teaching through mindful reflection. Specifically, the mCoP helped to transform the quality level of pre-service teachers' reflection to a higher level. This is important because a focus on quality metacognition helps new teachers develop awareness skills that can be used to improve their pedagogy. CoP created a space for the future teachers to examine their assumptions of inquiry practice in classroom contexts and built a network of encouraging support from experienced teachers that functioned to help the pre-service teachers beat the challenges of teaching inquiry in a real context. And finally, the mCoP provides the field of education with a model to use for developing preservice teachers' inquiry pedagogy.

\section{Future Investigation}

The findings of this study show that pre-service teachers, through cyclic teaching, support of $\mathrm{mCoP}$, and guiding questions gradually improve the quality of their reflections. However, what the data does not uncover is what happened exactly in the $\mathrm{mCoP}$ to lead to this positive outcome. Was it specifically the mentorship of cooperating teachers? The iterative nature of $\mathrm{mCoP}$ meetings providing experience with the process of reflection? Thus, future studies may explore core practices underlying the $\mathrm{mCoP}$ that foster reflective quality.

The data from this study also leaves us wondering in what ways reflective quality is linked to beginning teachers' beliefs and science teacher identity that are manifested and developed gradually through reflective interactions in $\mathrm{mCoP}$ activities. Since there are some studies that indicate reflection is a premise for cultivating change in teachers' beliefs (Decker et al., 2015) and that reflection is one of the key driving agents to forming teacher identity (Burhan-Horasanl and Ortaçtepe, 2016), what is the interplay between pre-service teachers' reflection, their beliefs on teaching and learning science, and how does this interaction lead to science teacher identity formation? Answers to these questions would provide meaningful guidelines on how to sustain pre-service teachers' beliefs and practice of inquiry while building a strong sense of professional identity.

\section{REFERENCES}

Abd-El-Khalick, F., Boujaoude, S., Duschl, R., Lederman, N.G., MamlokNaaman, R., Hofstein, A., Niaz, M., Treagust, D., \& Tuan, H.L. (2004). Inquiry in science education: International perspectives. Science Education, 88(3), 397-419.

Abell, S.K., \& Bryan, L.A. (1997). Reconceptualizing the elementary science methods course using a reflection orientation. Journal of Science Teacher Education, 8, 153-166.

Barnett, E., \& Friedrichsen, P.J. (2015). Educative mentoring: How a mentor supported a preservice biology teacher's pedagogical content knowledge development. Journal of Science Teacher Education, 26(7), 647-668.

Borko, H., Jacobs, J., Eiteljorg, E., \& Pittman, M. (2008). Video as a tool for fostering productive discussions in mathematics professional development. Teaching and Teacher Education, 24, 417-436.

Buczynski, S., \& Hansen, B. (2014). The Change Leader in Education: Roles and Strategies in the Differentiated Environment. London: Bridgepoint Education.

Burhan-Horasanl, E., \& Ortaçtepe, D. (2016). Reflective practice-oriented online discussions: A study on EFL teachers' reflection-on, in and foraction. Teaching and Teacher Education, 59, 372-382.

Bybee, R.W., Taylor, J.A., Garder, A., Scotter, P.V., Powell, J.C., Westbrook, A., \& Landes, N. (2006). The BSCS 5E Instructional Model: Origins and Effectiveness. Available from: https://www.media.bscs.org/bscsmw/5es/ bscs 5e full_report.pdf.

Decker, A., Kunter, M., \& Voss, T. (2015). The relationship between quality of discourse during teacher induction classes and beginning teachers' beliefs. European Journal of Psychology Education, 30, 41-61.

Densombe, M. (2014). The Good Research Guide: For Small-Scale Social Research Projects. $5^{\text {th }}$ ed. London: Open University Press.

Dewey, J. (1933). How We Think. Lexington: DC Heath \& Co Publishers.

Gallagher, J.J., \& Tobin, G.K., (Eds.), (1991). Interpretive Research in Science Education. Manhattan: National Association for Research in Science Teaching.

Ghaye, T. (2011). Teaching and Learning through Reflective Practice: A Practical Guide for Positive Action. $2^{\text {nd }}$ ed. London: Routledge.

Gill, M.G., Ashton, P.T., \& Algina, J. (2004). Changing preservice teachers' epistemological beliefs about teaching and learning in mathematics: An intervention study. Contemporary Educational Psychology, 29(2), 164-185.

Goodman, J. (1991). Using a methods course to promote reflection and inquiry among preservice teachers. In: Tabachnick, B., \& Zeichner, K., 
(Eds.), Issues and Practices in Inquiry-Oriented Teacher Education. London: Falmer Press. pp. 56-76.

Gore, J.M., \& Zeichner, K.M. (1991). Action research and reflective teaching in preservice teacher education: A case study from the United States. Teaching and Teacher Education, 7(20), 119-136.

Hansen, B., Buczynski, S., \& Plunkett, K. (2015). Curriculum and Instruction for the $21^{s t}$ Century. London: Bridgepoint Education.

Hatton, N., \& Smith, D. (1995). Reflection in teacher education: Towards definition and implementation. Teaching and Teacher Education, 11(1), 33-49.

Inoue, N., \& Buczynski, S. (2011). You asked open-ended questions, and now what? Understanding stumbling blocks in inquiry-based lessons. The Mathematics Educator, 20(2), 10-23.

Isaacs, W. (1999). Dialogue and the Art of Thinking Together: A Pioneering Approach to Communicating in Business and in Life. New York: Currency.

Jones, M.G., Gardner, G.E., Robertson, L., \& Robert, S. (2013). Science professional learning communities: Beyond a singular view of teacher professional development. International Journal of Science Education, 35(10), 1756-1774.

Kang, E.J.S., Bianchini, J.A., \& Kelly, G.J. (2013). Crossing the border from science student to science teacher: Preservice teachers' views and experiences learning to teach inquiry. Journal of Science Teacher Education, 24, 427-447.

LaBoskey, V. (1994). Development of Reflective Practice. New York: Teachers College Press.

Lane, R., McMaster, H., Adnum, J., \& Cavanagh, M. (2014). Quality reflective practice in teacher education: A journey towards shared understanding. Reflective Practice, 15(4), 481-494.

Larrivee, B. (2008). Meeting the challenge of preparing reflective practitioners. The New Educator, 4(2), 87-106.

Lave, J., \& Wenger, E. (1991). Situated Learning: Legitimate Peripheral Participation. Cambridge: Cambridge University Press.

Leijen, A., Valtna, K., Leijen, D.A.J., \& Pedaste, M. (2012). How to determine the quality of students' reflections? Studies in Higher Education, 37(2), 203-217.

Lin, H., Hong, Z., Yang, K., \& Lee, S. (2013). The impact of collaborative reflections on teachers' inquiry teaching. International Journal of Science Education, 35(8), 3095-3116.

Lincoln, Y.S., \& Guba, E.G. (1985). Naturalistic Inquiry. New York: SAGE.

Lotter, C. (2004). Preservice science teachers' concerns through classroom observations and student teaching: Special focus on inquiry teaching. Science Educator, 13(1), 29-38.

Lotter, C.R., \& Miller, C. (2017). Improving inquiry teaching through reflection on practice. Research in Science Education, 47, 913-942.

Loughran, J. (2014). Professionally developing as a teacher educator. Journal of Teacher Education, 65(4), 271-283.

Mezirow, J. (1995). Transformation theory of adult learning. In: Welton, M.R., (Ed.), Defense of the Life World. New York: State University. pp.39-70.
Mezirow, J. (1997). Transformative learning: Theory to practice. New Directions for Adult and Continuing Education, 74, 5-12.

Ministry of Education. (2002). The Manual of Science Teaching and Learning. Thailand: Express Transportation Organization of Thailand.

Ministry of Education. (2017). Standards and Indicators of Mathematics, Science, and Geography (Amendment B.E. 2560), Under National Core Curriculum B.E. 2551. Thailand: The Agricultural Cooperative Federation of Thailand, Ltd.

Moon, J.A. (2004). Reflection in Learning and Professional Development. London: Routledge-Falmer.

National Research Council (NRC). (2000). Inquiry and the National Science Education Standards: A Guide for Teaching and Learning. Washington, DC: The National Academies Press.

National Research Council (NRC). (2013). Next Generation Science Standards: For States, by States. Washington, DC: The National Academies Press.

Piaget, J. (1961). The genetic approach to the psychology of thought. Journal of Educational Psychology, 52(6), 275-281.

Roehrig, G.H., \& Luft, J.A. (2004). Constraints experienced by beginning secondary science teachers in implementing scientific inquiry lessons. International Journal of Science Education, 26(1), 3-24.

Roy, R. (2018). Making the Transition: Examining Reflective Practice as a Premise to Develop Teacher Professional Knowledge and Skill in Science during Student Teaching, Unpublished Doctoral Dissertation. Bloomington: Indiana University.

Saarni, C. (2011). Emotional Development in Childhood. Available from: http://www.child-encyclopedia.com/emotions/according-experts/ emotional-development-childhood.

Shulman, L.S. (1987). Knowledge and teaching: Foundations of the new reform. Harvard Educational Review, 57(1), 1-22.

Smith, D., \& Engenmann, J. (2015). Exploring teacher induction: Collaborative self-studies across institutions. Journal of Education and Training Studies, 3(3), 156-167.

Sullivan-Watts, B.K., Nowicki, B.L., Shim, M.K., \& Young, B.J. (2013). Sustaining reform-based science teaching of preservice and in service elementary school teachers. Journal of Science Teacher Education, 24, 879-905.

van Manen, M. (1977). Linking ways of knowing with ways of being practical. Curriculum Inquiry, 6(3), 205-228.

Wenger, B., \& Trayner, B. (2015). Introduction to Community of Practice: A Brief Overview of the Concept and Its Uses. Available from: https:// www.wenger-trayner.com/introduction-to-communities-of-practice.

Yoon, H.G., Joung, Y., \& Kim, M. (2012). The challenges of science inquiry teaching for pre-service teachers in elementary classrooms: Difficulties on and under the scene. Research in Science Education, 42(3), 589-608.

Zembal-Saul, C., Blumenfeld, P., \& Krajcik, J. (2000). Influence of guided cycles of planning, teaching, and reflection on prospective elementary teachers' science content representations. Journal of Research in Science Teaching, 37(4), 318-339. 


\section{Interview Protocol:}

\section{APPENDIX A}

1. Did the lesson achieve the learning objectives?

2. How do you know if the lesson achieved or did not achieve the learning objectives?

3. What did you do in this class that supports or did not support children learning?

4. What did you do in this class that you would choose to do (or not to do) it again?

5. What is your concern about this lesson? Why do you have this concern?

6. If this lesson was taught using an inquiry-based learning pedagogy? Why?

a. What were the key features of scientific inquiry found in this lesson?

b. What were the key features of scientific inquiry missing from this lesson?

7. What would you like to improve in this lesson? How would you improve it? 